\title{
Implementation of Multicultural Education in Unschooling and Its Potential
}

\author{
Sarah Chase \\ Radford University \\ U. S. A. \\ Kristan Morrison \\ Radford University \\ U. S. A.
}

\begin{abstract}
Unschooling is a form of homeschooling in which parents allow children to self-direct their education. To determine if there was any evidence of unschoolers attending to the goals of multicultural education, we conducted a content analysis of a germinal resource-the 1977-1981 issues of Growing Without Schooling (GWS). Our analysis revealed that, in the early years, the content of this magazine depicted some degree of exposure to issues of oppression related to race, gender, and social class, but relatively rare engagement from the perspective of the marginalized, and minimal focus on taking social action to mitigate societal inequities.
\end{abstract}

KEYWORDS: unschooling, homeschooling, multicultural education, curriculum conceptions, content analysis

\author{
Unschooling Defined \\ Growing Without Schooling \\ Methods \\ Results \\ Discussion \\ Limitations of the Study \\ Conclusions and Further Study \\ References \\ Author Contact
}

Student-directed learning in the home, termed unschooling (Petrovic \& Rolstad, 2016), is a form of education in which parents eschew a formal or standardized curriculum and instead allow their children curricular freedom. In unschooling, "the learner's freedom and autonomy [is] limited as little as possible...learning always starts with the individual's needs, goals, and desires, and not with any supposed body of knowledge or societal demands" (Miller, 2004, para. 9). We sought to determine if there was any evidence of unschoolers attending to the goals of multicultural education. We chose to use the resource Growing Without Schooling (GWS), a magazine targeted to unschooling families, as a data set reflective of the values and actions of the unschooling community, hoping to uncover the degree to which unschooling families and proponents gave 
attention to the development of multicultural competencies. These competencies include knowledge of cultural and racial differences and issues, especially those involving marginalized populations in a society; analysis of systemic oppressions; and engagement in actions aimed at creating a world that is fair, just, and characterized by universal equitable opportunities. We conducted a content analysis of the first 19 issues of GWS (1977-1981), framed by the stages of curricular reform outlined by James Banks in 1989.

\section{Unschooling Defined}

Unschooling is a form of, or approach to, homeschooling. The National Center for Education Statistics (2016) estimated that the number of children engaged in homeschooling was around 1.8 million in 2012 (most recently available numbers). Numbers of unschoolers in the United States are difficult to determine, as not all adherents claim the label; nor is there agreement as to what the label means. At best, we can only estimate that some percentage of homeschoolers are unschoolers. Gray and Riley (2013) described unschooling in the following way:

Unschoolers do not send their children to school and they do not do at home the kinds of things that are done at school. More specifically, they do not establish a curriculum for their children, they do not require their children to do particular assignments for the purpose of education, and they do not test their children to measure progress. Instead, they allow their children freedom to pursue their own interests and to learn, in their own ways, what they need to know to follow those interests. They also, in various ways, provide an environmental context and environmental support for the child's learning. Life and learning do not occur in a vacuum; they occur in the context of a cultural environment, and unschooling parents help define and bring the child into contact with that environment. (Gray \& Riley, 2013, p. 7)

As of this writing, there is no one agreed-upon approach to unschooling; different families have different motivations and purposes/end goals in unschooling their children (Gray \& Riley, 2013; Kapitulik, 2011; Morrison, 2016; Morrison, in press; Ricci, 2011; Schenwar, 2008; Wheatley, 2009), and thus they approach unschooling with differing degrees of structure in regards to content and pedagogy, some with almost no structure or mandates for children at all (Neumann \& Guterman, 2017). In an attempt to better understand this very heterogeneous movement, Petrovic and Rolstad (2016) have suggested "a normative philosophy of unschooling...[in which] homeschoolers must have particular motivations, purposes, and design to be considered unschoolers" (p. 5). They argue that a family cannot properly consider themselves to be unschoolers unless they require,

experiences that serve to inculcate specific dispositions necessary to democratic society. While we cannot pretend to be able to develop a finite list of such things, we might begin with mutual respect of people merely for their personhood, à la a notion of inalienable rights. We might include 
recognition of diversity of experiences, cultural attachments, religious affiliations, among other things that inform different people's view of a good life. (p. 5)

Petrovic and Rolstad (2016) further argue that unschoolers should come to "understand their society and their role in troubling the assumptions and contradictions inherent to it, especially as those contradictions undermine the autonomy of others" (p. 6).

What must occur [within unschooling], then, is critical engagement with the meaning in the experience. This is what Freire refers to as conscientization: The process by which people become knowing subjects, becoming aware of their sociocultural and political reality, the contradictions therein, and their capacity to transform that reality. (p. 9)

But do most unschoolers meet Petrovic and Rolstad's criteria detailed above? Unschooling, as mentioned earlier, is a form of homeschooling, and homeschooling parents are predominantly White and middle-class (National Center for Education Statistics, 2016) and likely have been educated in our system of public education, which is not well known for having a deep emphasis on multicultural or social justice education. Thus, many unschooling parents may not have practice in challenging the hegemony of dominant discourses within a society, or in offering up alternative ways of understanding the world, power, and knowledge. In a previous study (Morrison, in press), one of the authors found that while there are some unschooling parents who seem to consciously recognize the necessity for all people (their children included) to understand societal inequities and the experiences and perspectives of those unlike themselves, there were also a number of unschooling respondents who seemed to evidence a lack of criticality about their own subjectivities. They expressed meritocratic or deficit viewpoints about capitalist/democratic culture, referenced issues of inequality in the past tense, or simply did not see much value in adopting a critical stance, at least as related to marginalized groups in society. This variance in responses from unschoolers is part of what prompted this current research.

\section{Growing Without Schooling}

The phenomenon of unschooling has been gaining more scholarly attention in the past decade, especially with the launching, in 2006, of the Journal of Unschooling and Alternative Learning and the 2012 inception of Other Education: The Journal of Educational Alternatives. Some of the research on unschooling, as well as the un- or home-schooling entries in a number of encyclopedias related to education topics, mentions a resource used by many unschooling families, namely a magazine entitled Growing Without Schooling (Collom, 2007; Gray \& Riley, 2013; Kapitulik, 2013; Kunzman, 2014; Mayberry, 2007; Ray, 2012).

This magazine/newsletter was founded in 1977 by the educator John Holt, who coined the term unschooling. Between 1977 and 1985, Holt served as the 
primary editor of the magazine, and after his death in 1985, assistant editors Susannah Sheffer and Patrick Farenga took over the publication. While the format of the magazine changed somewhat after Holt's death, the magazine's content remained largely the same: a collection of articles, letters, book reviews, interviews, and listings of resources available for purchase, written either by the editors or by readers who were unschooling. In 2001, the magazine ceased publication after its 143 rd issue. While scanned copies of all issues are available online (https://issuu.com/patfarenga/stacks/bb179dac91264c10bb183f89bf95593 5 ), they are not easily searchable. In recent years, Patrick Farenga and JUAL founder Carlo Ricci began a project to digitize and electronically publish all 143 issues. As of this writing, the only fully published volume is of issues 1-19 (Farenga $\&$ Ricci, 2016). We conducted our research on only these available issues.

The repeated mention of GWS in the scholarly record related to unschooling indicates its value within the unschooling community as a germinal resource. As such, it has the potential to provide researchers with insights into the educational experiences of unschoolers. Further, it is imbued with its authors' orientations to the world, which inevitably include their own interests, assumptions, and approaches "about ways of knowing and about how teachers and students [in the case of unschooling, children and those around them] are to be understood" (Aoki, 2004 , p. 160). Thus, we recognized that the magazine could serve not only as a reflection of the lives of contributors and readers, but it could also have played a significant role in influencing those readers' worldview and actions. This resource was thus ripe for studies employing content analysis methods (Krippendorf, 2013).

\section{Methods}

In order to explore the degree to which unschooling families and proponents gave attention to the development of multicultural competencies, we examined GWS with respect to stages of multicultural curriculum reform, originally established by James Banks (1989) and adjusted for use in the context of unschooling. This provided us with a framework with which to analyze GWS in a manner that facilitates comparison with the public school curriculum.

\section{Content Analysis and Process}

This study was a "directed content analysis" (Hsieh \& Shannon, 2005, p. 1281) in that existing theory, that of James Banks' (1989) approaches to multicultural curriculum reform, helped focus our methodology. In his work, Banks lays out a four-stage process to curricular reform that aims to create equitable educational opportunities for students by ensuring that the school curriculum reflects the diversity of groups in society and their experiences. Briefly, he argues that much existing school curriculum is mono-cultural, focused primarily on the dominant racial and cultural groups in society (White, male, middle class or higher, 
and heterosexual). In order to make the curriculum more inclusive, or multi-cultural, schools and teachers can move through a four-stage process. The first stage (Contributions) involves bringing in mentions of ethnic heroes or special ethnic events-this first stage is sometimes called "Heroes and Holidays." The second stage (Additive) involves "the addition of content, concepts, themes, and perspectives to the curriculum without changing its basic structure, purposes, and characteristics" (Banks, 1989, p. 17). The third stage (Transformative) encourages "students to view concepts, issues, themes, and problems from several ethnic perspectives and points of view" (Banks, 1989, p. 18). The fourth stage (DecisionMaking and Social Action) "require[s] students to make decisions and to take actions related to the concept, issue, or problem they have studied [related to ethnic topics]" (Banks, 1989, p. 18).

In the issues of GWS examined in this study, we were looking for inclusion of topics, discussions, or entire articles related to diverse groups in our society, especially those systematically excluded from the mainstream curriculum. Such groups were thus our initial coding categories (Hsieh \& Shannon, 2005). First, we each independently read through the 19 issues looking for words related to some sort of minority or "other" status in our society. Once we identified such words, we marked them to examine their context later. After reading all 19 issues, we met over a period of weeks to discuss each marked item to develop a list of "trigger terms," so-called because they signaled to us that we needed to take a closer look at the context of the word. After agreeing upon and developing our list of trigger terms, we created categorical distinctions (Krippendorf, 2013) for our identified triggers: Race, Gender, and Social Class. While we had originally thought to include other categories of marginalized groups (people with disabilities, people on the LGBT spectrum, etc.), our reading of the first 19 issues revealed either an absence of any mentions of these groups (LGBT), or very convoluted understandings and explanations of these groups (people with disabilities). Thus, for the sake of clarity, we excluded those two categories. Further, we decided to exclude mentions of cultures abroad from the Race category in order to narrow the focus to intra-country race discussions. After settling on three categories of marginalized populations, we then examined the context of each identified trigger term (sentences before and after the trigger term) to determine what was being discussed around that term. If the trigger term was used in a way that was unrelated to issues of marginalization, we excluded it. For example, "oh boy" was excluded while "The couple has hired a male babysitter" was included; "it was a rich sauce" was excluded while "they lived in a rich neighborhood" was included. After the above-mentioned exclusions, we had an overall list of trigger terms as well as total counts, as shown in Table 1 below. The trigger terms and their context became our units of analysis, in which context was subjectively determined to start and end in a way that completely contains the material relevant to the trigger term mentioned. 
Table 1.

Trigger Terms and Quantity

\begin{tabular}{|ll|l|l|}
\hline \multicolumn{2}{|c|}{ SES } & \multicolumn{1}{c|}{ Gender } & \multicolumn{1}{c|}{ Race } \\
\hline Poor & Destitute & Girls & Indians \\
Needed every & Wealth(y) & Boys & Black \\
penny & Slave labor & Woman & Race/racial \\
Working class & Ghetto & The body & Japanese \\
Poverty & Broke & Sex & Minority \\
Rich & No money & Father & Color \\
Middle class & Privileged & Mother & Ethnic \\
Affluent & Welfare & Male & Latin American \\
Low-income & & Opposite sex & White \\
\hline $\begin{array}{l}\text { 143 references in } \mathbf{7 5} \text { distinct } \\
\text { articles }\end{array}$ & & 44 references in $\mathbf{3 0}$ & $\mathbf{5 6}$ references in $\mathbf{4 0}$ \\
distinct articles
\end{tabular}

Once we identified the 224 units of analysis (contextualized references to race, gender, and social class), we then discussed ways to adapt Banks' four stages of curriculum integration to the text of GWS. The adaptation was not fully a parallel application, for GWS is not a curriculum in the traditional sense of being a pre-planned, "sequential and developmental" product (Banks \& Banks, 2015, p. 237), filled with particular content and knowledge directly aimed at developing certain characteristics and dispositions. In other words, GWS does not represent a "curriculum as plan" (Aoki, 2004). Rather, GWS is more aligned with a view of curriculum as "self-actualization" (Eisner \& Vallance, 1974) or "curriculum-as-lived" (Aoki, 2004). In these conceptions of curriculum, there is no set content that all children are expected to learn, though the interaction of the child with self-chosen content of any kind is seen as necessary for the child to self-actualize. Because of this disconnect between conceptions of curriculum in Banks' theory and the GWS data set, we were compelled to modify Banks' stages somewhat for the purposes of coding our 224 units, as outlined in Table 2 below.

Cases that seemed to fit multiple categories were coded in all applicable categories except when membership in one category implied membership in the other. When an agreement could not be reached after discussion regarding appropriate coding, the case was left out of analysis. This occurred only once. After coding was completed, all data were checked for consistency by category. 
Table 2

Coding of Data as Related to Theoretical Frame

\begin{tabular}{|c|c|}
\hline Banks' (1989) Stages & Interpretation as Applied to GWS \\
\hline $\begin{array}{l}\text { Stage 1: Contributions Approach } \\
\text { - Includes tangible aspects of non- } \\
\text { mainstream cultures (e.g., food, } \\
\text { clothing, holiday traditions, etc.) as } \\
\text { well as heroes } \\
\text { - Overall goals and orientation of } \\
\text { mainstream curriculum remain } \\
\text { unchanged } \\
\text { - The class studies little or nothing } \\
\text { about the non-mainstream group } \\
\text { before or after. }\end{array}$ & $\begin{array}{l}\text { Level } 1 \\
\text { - Word or phrase used as a descriptor } \\
\text { - Little to no mention about the defining group } \\
\text { characteristic (socio-economic status, race, } \\
\text { gender) before or after the descriptor in the } \\
\text { text } \\
\text { - Decontextualized from any sense of a } \\
\text { problem with inequity or marginalization } \\
\text { between groups } \\
\text { - Little or no mention of the advantages or } \\
\text { disadvantages these groups face in society } \\
\text { except as the natural or expected state of } \\
\text { things. }\end{array}$ \\
\hline $\begin{array}{l}\text { Stage 2: Additive Approach } \\
\text { - Some new content, concepts, and } \\
\text { themes on non-mainstream } \\
\text { groups are included } \\
\text { - No major structural or } \\
\text { philosophical change occurs to the } \\
\text { mainstream curriculum }\end{array}$ & $\begin{array}{l}\text { Level } 2 \\
\text { - } \quad \text { Trigger word used } \\
\text { - } \quad \text { Context provided indicates something } \\
\text { problematic about the social relations } \\
\text { between the different groups in society } \\
\text { - } \quad \text { No solutions offered } \\
\text { - } \\
\text { Author/editor wrote from the vantage point of } \\
\text { a person not in that marginalized group } \\
\text { (mainstream perspective) }\end{array}$ \\
\hline $\begin{array}{l}\text { Stage 3: Transformative Approach } \\
\text { - Curriculum structure is changed } \\
\text { - Enables students to view } \\
\text { concepts, issues, themes, and } \\
\text { problems from several ethnic } \\
\text { perspectives and points of view }\end{array}$ & $\begin{array}{l}\text { Level } 3 \\
\text { - } \quad \text { Trigger word used } \\
\text { - } \text { Context provided indicates something } \\
\text { problematic about the social relations } \\
\text { between the different groups in society } \\
\text { - } \quad \text { No solutions offered } \\
\text { - } \text { Author/editor wrote from the vantage point of } \\
\text { a member of the marginalized group (non- } \\
\text { mainstream perspective) }\end{array}$ \\
\hline $\begin{array}{l}\text { Stage 4: Social Action Approach } \\
\text { - Students acquire skills of political } \\
\text { efficacy } \\
\text { - School leads students in praxis } \\
\text { (reflective social criticism coupled } \\
\text { with actions aimed at social } \\
\text { change) }\end{array}$ & $\begin{array}{l}\text { Level } 4^{*} \\
\text { - } \text { Trigger word used } \\
\text { - } \quad \text { Context provided indicates something } \\
\text { problematic about the social relations } \\
\text { between the different groups in society } \\
\text { - } \text { Includes examples of some sort of social } \\
\text { action toward addressing the problem and } \\
\text { creating a more just and equitable society }\end{array}$ \\
\hline \multicolumn{2}{|c|}{$\begin{array}{l}{ }^{*} \text { Note. Level } 4 \text { was subdivided to allow for distinction between solutions offered or } \\
\text { implemented by members of the marginalized group for themselves }(4-1 \mathrm{a} \text { and } 4-1 \mathrm{~b} \text {, } \\
\text { respectively) and solutions offered or implemented by a member of the mainstream for } \\
\text { marginalized others ( } 4-2 \mathrm{a} \text { and } 4-2 \mathrm{~b} \text { respectively). }\end{array}$} \\
\hline
\end{tabular}




\section{Results}

The numerical results of this study are broken down according to level and provided in Table 3. Broad themes across categories of SES, Gender, and Race, and meaningful patterns within categories are discussed after the table.

Table 3

Percentages of Level References

\begin{tabular}{|c|c|c|c|}
\hline \multirow[t]{2}{*}{ Level } & \multicolumn{3}{|c|}{$\begin{array}{c}\text { Percentage of references at } \\
\text { this level out of all trigger } \\
\text { term references by } \\
\text { cateqory }\end{array}$} \\
\hline & $\underset{(n=143)}{S E S}$ & $\begin{array}{l}\text { Gender } \\
(n=44)\end{array}$ & $\begin{array}{l}\text { Race } \\
(\mathrm{n}=56)\end{array}$ \\
\hline $\begin{array}{l}\text { 1- Reference as only a descriptor of marginalized } \\
\text { group }\end{array}$ & $40 \%$ & $68 \% *$ & $45 \%$ \\
\hline $\begin{array}{l}\text { 2- Reference to marginalization, made by someone } \\
\text { not in marginalized group }\end{array}$ & $29 \%$ & $16 \%$ & $41 \%$ \\
\hline $\begin{array}{l}\text { 3- Reference to marginalization, made by someone } \\
\text { in marginalized group }\end{array}$ & $7 \%$ & $2 \%$ & $2 \%$ \\
\hline 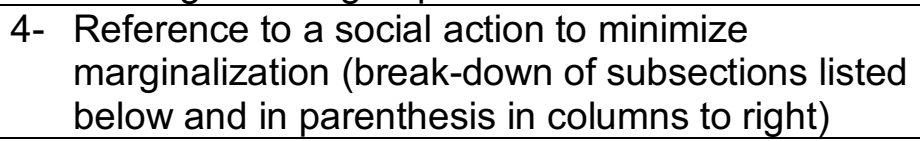 & $26 \%$ & $14 \%$ & $14 \%$ \\
\hline $\begin{array}{l}\text { (4-1a) - action suggested to marginalized person to } \\
\text { help self }\end{array}$ & $(9 \%)$ & $(7 \%)$ & $(2 \%)$ \\
\hline $\begin{array}{l}\text { (4-1b) - action done by marginalized person to help } \\
\text { self }\end{array}$ & $(6 \%)$ & $(7 \%)$ & $(7 \%)$ \\
\hline $\begin{array}{l}\text { (4-2a) - action suggested to non-marginalized person } \\
\text { to help others }\end{array}$ & $(7 \%)$ & $(0 \%)$ & $(2 \%)$ \\
\hline $\begin{array}{l}\text { (4-2b) - action done by non-marginalized person to } \\
\text { help marginalized others }\end{array}$ & $(5 \%)$ & $(0 \%)$ & $(5 \%)$ \\
\hline
\end{tabular}

\section{Level 1}

As can be seen in Table 3 above, of the 224 coded units, Level 1 descriptors were the numerical majority in each category (SES, gender, and race), followed, in order, by Level 2, 4, and then 3. An example of an item coded at Level 1 (with trigger term bolded) is the following:

Ten years earlier, I had served for a few weeks as consultant to a program to teach reading to adult illiterates in Cleveland, Ohio. Most of the students were from thirty to fifty years old; most were poor; about half were black, 
half white; most had moved to Cleveland either from Appalachia or the deep South [Issue 6, September 1978]. (Farenga \& Ricci, 2016, p. 106)

\section{Problems Identified in Levels 2 and 3}

As seen in Table 3 above, we coded $16-41 \%$ of our units of analysis at Level 2 and only $2-7 \%$ of our units of analysis at Level 3 . Some representative examples of each level include the following (with trigger term bolded).

Level 2

We can finally imagine that Mozart's sister might have...not been treated like a girl but we have not yet come to understand that the same kind of attitudes prevent all children from realizing their full potential [Issue 19, February 1981]. (Farenga \& Ricci, 2016, p. 596)

Level 3

As a welfare mother I get additional hassles about schooling for my kids [Issue 5, July 1978] (Farenga \& Ricci, 2016, p. 89)

There were significant similarities across the problems identified in Level 2 and 3 , and thus it makes sense to present them in tandem. Members of nonmarginalized groups (Level 2 authors) and members of marginalized groups (Level 3 authors) both identified similar problems with a particular group's marginalization in society. They raised the issue of discriminatory treatment in society (past and present) that manifested in the form of low quality education (including more rote/strict teaching, fewer opportunities for freedom and creativity, insulting treatment or being ignored by teachers, class-biased standardized tests, more stringent application of rules), lower work-compensation levels, laws not applied to all groups equitably, invisibility in cultural products and media, and abusive or violent treatment at the hands of others (e.g., Jim Crow-era events, slavery). They further argued that this discriminatory treatment leads to diminished access to high-quality resources, opportunities, and/or networks (these include such things as transportation, activities which broaden one's horizons, material goods, adequate and comfortable housing, high quality food), as well as the development of negative social-emotional characteristics (including lower self-esteem, lower self-confidence, higher stress, and lowered ability to demonstrate pro-social behaviors).

\section{Solutions Offered in Level 4}

Within Level 4, we coded actions that were either suggestions for (4-1a) or examples of (4-1b) people in marginalized groups helping themselves overcome identified problems related to their marginalization, or suggestions for (4-2a) or examples of (4-2b) people in non-marginalized groups helping those in 
marginalized groups. Table 3 above depicts the relative number of references in each of these four categories.

Representative examples of each of the four sub-categories can be found below (again with trigger terms bolded).

4-1a

Those who object to this [depictions of gender-specific roles, such as males for doctors, females for nurses] can very easily read and explain the stories so as to make many of these male characters into women. Sometimes they may have to re-write a word in the text, often not [Issue 13, March 1980]. (Farenga \& Ricci, 2016, p. 354)

4-1b

She worked as a carpenter in an all-male shop! [Issue 14, May 1980] (Farenga \& Ricci, 2016, p.363)

\section{4-2a}

I propose that schools, or people not sending their children to any school, or anyone who wants to make it easier for children to discover how to read, use as one of their "reading readiness materials" the large print edition of the N.Y. Times.... In low income communities, it might actually be put up on the walls of buildings or the windows of stores, for children (and others) to look at [Issue 5, July 1978]. (Farenga \& Ricci, 2016, p.86)

\section{$4-2 b$}

He has worked long and closely with Roxbury's Augusta Bailey to provide vegetables that are staples of the black diet and others that are less familiar [Issue 13, March 1980]. (Farenga \& Ricci, 2016, p. 342)

Themes of social actions emerged across all four categories and included advocating publicly for change, creating new resources (e.g., publications) or programs, delivering programs (e.g., teaching others/sharing talents), donating/sharing one's resources, fighting within (or supporting those fighting within) the legal system, ignoring established rules/expectations, learning new skills on own or with freely available resources (e.g., taking part in some established program), rejecting labels imposed by others, repurposing existing resources or using them in ways not expected (stepping outside of/rejecting normative behaviors), and using one's privilege to assist those who do not have privileges in a given situation (e.g., as a judge in a court case).

\section{Discussion}

Each level categorized in this study represents a stage of multicultural curriculum implementation and carries implications for the value placed on perspective-taking and social action. However, it is necessary to see these trends 
in the historical context in which this volume of GWS was written and to discuss philosophical implications identified in our analysis.

\section{Historical Context}

The time frame of the issues in our data set, as mentioned earlier, was 1977-1981. Gorski (1999) traced the history of multicultural education and showed that in the 1980s there was an emergence of scholarship on this topic by a number of progressive education activists and researchers. Further, an informal review of word usage over time using Google Books NGram Viewer (Michel et al., 2010) supports the idea that the concepts and terms of multicultural education that might be in use today (e.g., multicultural, LGBTQ, etc.) were not yet in popular parlance when the first 19 issues of GWS were published. This perhaps explains the reason why so few gender and race trigger terms, as compared to socioeconomic status trigger terms, emerged in our first coding of the issues. Unschooling that focuses on a more radical social agenda, along the lines advocated by Petrovic and Rolstad (2016), might be a more recent phenomenon. For example, Schenwar (2008) cited a discussion with an unschooling mother who believed that "queer, feminist homeschooling is on the rise [italics added] because parents see it as an escape from the rampant sexism, homophobia, and trans-phobia of public schools" (p. 27).

\section{Level 1}

As mentioned in the results section, we coded the majority of trigger term references as Level 1. We found that Level 1 references in GWS used trigger words most often as descriptors of the state of things. The main point of the article was another topic or issue.

Banks (1989) warned that his theory's Stage 1 Contributions Approach (roughly equivalent to our Level 1 references) "often results in the trivialization of ...cultures... and the reinforcement of stereotypes and misconceptions" (p. 17). The trivialization Banks warned of seemed to be happening in our Level 1 references at times. For example, an unschooling father, in a letter to John Holt published in Issue 5 (July 1978) of GWS, wrote:

I just remembered a story about some Navajo children in a reservation school. Whenever a group of them were sent to the board to do an arithmetic problem, they would all finish at the same time. The fast ones would wait for the slower ones to figure it out so as not to embarrass them. (Farenga \& Ricci, 2016, p. 94)

While the father was speaking approvingly of this non-competitive practice, he was also feeding in to a stereotype of the "noble savage" who rarely thinks only of himself, but always of his tribe mates. 


\section{Level 2}

Second to Level 1 references in quantity coded were Level 2 references. When Level 2 is broken down by category, race references in Level 2 were roughly equal to the number of race references in Level 1 . The temporal proximity of this volume of GWS with the African American Civil Rights Movement may explain the higher incidence of race mentions in Level 2 in relation to mentions of SES and gender in Level 2.

Banks also warned that his theory's Stage 2 Additive Approach (roughly equivalent to our Level 2 references) "fail[s] to help [children] view society from diverse cultural and ethnic perspectives and understand the ways in which the histories and cultures of the nation's diverse ethnic, racial, cultural, and religious groups are inextricably bound" (p. 18). This problem appeared in GWS Issue 10 (July 1979) with Holt's endorsement of the book The Education of Little Tree without any mention of the controversy surrounding the author of the book: in 1976, the New York Times published a piece suggesting that the novel was not written by a half-Cherokee writer, but actually a White man who was also a former speech writer for segregationist governor George Wallace ("Is Forrest Carter Really Asa Carter," 1976).

\section{Level 3}

Most of our Level 3 coding was in the category of Social Class; there was only 1 item coded in level 3 in both the Race and Gender categories. Families who unschool often give up one parent's income so that one parent can stay at home with the children (there are also instances of single parent unschooling). Perhaps this diminished income is the reason why we saw relatively more references from the perspective of people who identified themselves as lower income than we did marginalized genders or races. And even though we did code 10 Social Class references at Level 3, we did not get the sense that these writers saw themselves in the depths of the permanent underclass. For example, in Issue 4 (May 1978), a mother wrote in saying,

Here is my situation: I am deeply in debt, on account of having been in law school for the past three years. I decided to go to law school, as it happens, in response to the pressures of trying to support myself and my child through do-good jobs and welfare. (Farenga \& Ricci, 2016, p. 64)

The lack of perspective-taking that is characteristic of Level 3 reflects both the demographic homogeneity in the unschooling community and the childcentered philosophy of unschooling that may appear to run counter to "other"centered discourse. In addition, we found it notable that even though the most active homeschooling (and thus unschooling, as a subset) parent (the one who 
stayed home with the children) is generally the mother (National Center for Education Statistics, 2016), there was only one GWS contributor in the first 19 issues who identified herself as a feminist (thus as a marginalized woman).

The identity of the contributors does not preclude them from sharing resources (e.g., books, events) that conveyed the perspective of "others," though, and yet we saw quite little of that as well. This may perhaps have been due to the fact that the issues of the oppressed weren't of prominent concern to unschoolers. As an unschooling mother stated in Schenwar (2008), "It's easy to be color-blind when you're not exposed to racism; it's easy to 'ignore' gender when you're not confronted with sexism" (p. 32).

\section{Level 4}

As mentioned earlier, we sub-categorized Level 4 references as suggested actions or examples of members of a marginalized group acting to help themselves, and suggested actions or examples of members of a nonmarginalized group acting to help members of a marginalized group. The varying quantities of solution type by social category (SES, race, and gender) may reflect the views of the community on SES, race, and gender. SES had the highest percentage of solutions offered, with 39 solutions in 19 issues compared to 6 for gender and 9 for race. This may reflect the concerns of families who wish to unschool their children but find a lack of resources to be a barrier. This may also be a more familiar issue to the unschooling demographic.

The race category had the lowest relative percentage of Level 4 references, and most references were examples of actions taken rather than prescribed actions. According to our analysis of GWS, the unschooling community seems to avoid suggesting solutions for racial inequity, possibly due to their unfamiliarity with racial marginalization issues.

The gender category had the lowest total number of Level 4 references, and all Level 4 gender references were prescribed actions or examples of ways for families or individuals to help themselves overcome gender discrimination. There were no instances of suggested actions or examples of men helping to reduce gender discrimination.

\section{Parallels with Multicultural Education in Traditional Schools}

Our quantitative results parallel the findings of research regarding social justice/multicultural education in the United States' public preK-12 schools (Jupp \& Sleeter, 2016; Lee, Menkart, \& Okazawa-Rey, 1998; Miner, 2007; Nieto \& Bode, 2018). Specifically, much of the focus lies primarily in the exposure, or Heroes and Holidays, stage, and in the Additive stage. This predominance of Levels 1 and 2 and the subsequent lack of non-mainstream perspective-taking or social action 
may also be a consequence of the demographic composition of homeschoolers (predominantly White and middle class), of which unschoolers are a subset (The National Center for Educational Statistics, 2016). While Lee (in Miner, 2007) has indicated that raising children's awareness at the first two levels is preferable to a fully mono-cultural curriculum, she also argues that it is incumbent upon educators (including parents) to push through to higher levels. For the issues of GWS we reviewed, we found few items to code at Levels 3 and 4; however, implicit throughout the issues were other potential ways to address issues of inequity, ways that may be inherent to the unschooling philosophy.

\section{Unschooling Philosophy and Its Positive Implication for Equity}

Our analysis of GWS suggests that unschoolers see the schools as a negative social context for individual development. Unschooling advocates seem to believe that removing children from the school context and facilitating learning in the home setting encourages positive individual development because the child is enmeshed in a different social context, one untainted by influences of inequitable social norms. This seems to suggest that unschooling (due to its setting and approach) has a potential for "naturally" fighting inequity. For example, in Issue 16 (September 1980) a father wrote:,

I suspect that the lack of any social problems is the consequence of what my boys haven't learned-sexism, racism, etc. While I can well understand the concerns so often expressed in GWS that schools don't help kids learn much, I am less upset about that fact than I am about all the garbage that kids do [emphasis in original] learn in schools. (Farenga \& Ricci, 2016, p. 446)

In addition, we identified frequent discussions of a general openness to others. These instances did not reference any specific category of inequity, but indicated a philosophical basis for encouraging critical thought with regard to social systems as well as a desire to engage with others who might be different from themselves. For example, in Issue 18 (December 1980), a mother stated the following, inviting people to live with her family:

We are willing to share our home and the life we love in return for the labor and knowledge of another. Witnessing the reaction of a newcomer to this type of life [self-sufficient, no TV or radio] will also be enriching. This would have to be arranged on a personal basis with anyone interested, of course, but we are looking for people of clean living habits. We feel a bit shaky making this offer, as there are all kinds of kooks and weirdo's [sic] in the world, but we still feel that there would be many benefits to all parties. (Farenga \& Ricci, 2016, p. 523) 


\section{Unschooling Philosophy and Its Negative Implications for Equity}

In addition to positive implications for equity inherent in the unschooling philosophy, we also encountered some negative implications. In unschooling, children choose what they study, and what they study is often dependent on their exposure to the world. There exists a risk that children, because they "don't know what they don't know" or experience, may remain ignorant of the situations and experiences of others and will subsequently fail to recognize and address social inequities. In addition, since unschoolers pursue their own interests over a prescribed curriculum, it is possible that unschoolers may not choose to pursue areas of discrimination or systemic disadvantages, which necessarily require adopting perspectives other than one's own. Even if parents wish for their children to engage with certain topics such as multiculturalism, the children still may not make the choices their parents hope for. For example, in Issue 10 (July 1979), an unschooling father wrote to John Holt, stating,

It's hard work, of course, for us to adjust ourselves to the kids' interests. They wake up every morning curious but, alas, rarely curious about the particular topics that we might be prepared to talk about or might by our standards prefer they be curious about-that's when temptation rears its head and must be ruthlessly suppressed. It's a waste of time and quickly degenerates into intellectual bullying to try to sidetrack a kid onto topics you think he should be learning. (Farenga \& Ricci, 2016, p. 252)

As this example illustrates, unschooling families seem to support their children's agency through allowing them to explore their interests freely, but they also realize that following the unschooling philosophy can limit their agency in encouraging exploration of certain topics and perspectives. While GWS contributors seemed to believe they could not force their children to focus on certain topics, the environments they created were not neutral. Some unschoolers grappled with this idea, as evidenced by one mother who wrote that her "greatest concern is that I don't want to slant my children's view of life all through 'mother-colored' glasses... [ellipses in original]" to which Holt responded,

You are an influence on your children, and an important one, but by no means the only one, or even the only important one. How they later see the world is going to be determined by a great many things, many of them probably not to your liking, and most of them out of your control. On the other hand, it would be impossible, even if you wanted to, not to have some influence on your children's view of life. (Farenga \& Ricci, 2016, p. 364-365)

Another impediment to equity implicit in the unschooling philosophy is connected to the notion of cultural capital (e.g., social assets of a person such as education, intellect, style of speech and dress, which promote social mobility in a stratified society) (Bourdieu, 1986). A person must possess some cultural capital in order to feel empowered enough to embrace the unschooling philosophy, which 
runs so counter to normative approaches to education. Thus, families from marginalized groups may not have the same levels of freedom to engage in unschooling as a family with cultural capital (Kirschner, 2008). And if marginalized families do take the step of choosing unschooling, they may face extra hardships, or a two-fold rejection by society-first, for their marginalized group membership, and second, for their educational choice. An example of a mother struggling with this two-fold rejection appeared in Issue 5 (July 1978).

My daughter, 6, has attended schools on and off for a few years and always learns more in the "off" times!.... I can see "socialization" creeping into her ways and I want her out of school! As a "welfare mother," I get additional hassles about schooling for my kids.... I may be able to arrange some "home study" deal, but am afraid to ask the authorities for info, which could lead to my entrapment. They are already questioning my child's tardy and attendance record, so I'm trying to keep as low a profile as I can. (Farenga \& Ricci, p. 88-89)

\section{Limitations of Study}

This research has a number of limitations related to the data set and to our methods of coding that data. In these early issues of GWS, the author of a given piece is rarely identified, and if identification information is provided, it is limited (for example, we are not told the full name of contributors, how many children they unschool, how long they have unschooled, etc.). We thus are prevented from engaging in any sort of follow up with the authors to determine interpretation of certain phrases, or the author's intention; rather, we must do a great deal of inferring. And because there are only two of us engaged in this study, our inferences are limited to our subjectivities and to the inherent problems of attempting to do quantification of qualitative information. Furthermore, coding by topic rather than by article, since articles varied greatly in length, introduced error related to the subjective determination of the start and end of a topic. In the Gender category, the subjectivity complication was worsened by the gendered nature of the English language.

Another drawback to doing research on GWS is the very nature of the magazine itself-documents that are edited by one person (John Holt) and made up of various contributors' comments and ideas. These contributors voluntarily offered their writings to the magazine, and there is thus a self-selection bias present that might make the magazine unrepresentative of the unschooling population as a whole. For instance, there may have been a large body of unschoolers in this time period who focused heavily on socially reconstructive activities, but simply chose not to share their stories with Holt. Or Holt may have made a purposeful editorial choice to exclude any such contributions. Holt, at times, made comments that made us question whether he was deeply aware of his own biases and subjectivities. (We will explore these intriguing examples in a future study as they raise significant questions). Yet another limitation to this study 
is the fact that we only had searchable access to the first 19 issues that span the years 1977-1981, a period of time in which the topics of multicultural education had not appeared widely in mainstream consciousness.

\section{Conclusions and Further Study}

Despite the limitation of the study, the results are illuminating. References to marginalized groups in GWS appear mostly as mentions. According to the data, in the early years of GWS' publication it seems that unschoolers rarely engaged with multicultural context from the perspective of the marginalized and had a relatively small focus on taking social action to mitigate societal inequities. Unschooling seems to have the potential for natural, impactful solutions to problems of inequity in society, but the philosophy of unschooling may be at odds with the perspective-taking necessary for multiculturalism. However, these conclusions may be due to sampling from early in the unschooling movement and should be applied with the aforementioned limitations in mind. Further study is necessary to see if unschooling community identity develops past the isolationist and individualist tendencies seen in GWS Volume 1. It may be possible that GWS is going through an identity development process parallel to individual identity or racial identity development (e.g., Helms, 2014). To this end, examining later volumes of GWS and their relative inclusion of the stages of multicultural education may be informative.

During the course of our investigation, some other questions requiring further study arose related to implementation of multicultural education in the unschooling context. First, are a family's motivations for choosing to unschool related to the decision to implement multicultural education and the efficacy of those multicultural activities? Second, what can be learned from the unschooling approach to multicultural education that may help inform multicultural education in traditional schooling?

At the time of this writing, there is a slowly growing body of research on unschooling as a phenomenon, but there is no known research on multicultural education in unschooling. With further study, it may be possible not only to learn about the linkages of these two educational approaches, but also to learn from the strengths of multicultural education in unschooling to better implement such practices in other forms of education.

\section{References}

Aoki, T. T. (2004). Teaching as in-dwelling between two curriculum worlds. In W. F. Pinar \& R. L. Irwin (Eds.), Curriculum in a new key: The collected works of Ted T. Aoki (pp. 159-166). New York, NY: Routledge. 
Banks, J. A. (1989) Approaches to multicultural curriculum reform. Trotter Review, 3(3), 17-19. Retrieved from http://scholarworks.umb.edu/trotter_review/ vol3/iss $3 / 5$

Banks, J., \& Banks, C. (2015) Multicultural education: Issues and perspectives (9th ed.). Boston, MA: Allyn and Bacon.

Bourdieu, P. (1986) The forms of capital. In J. Richardson (Ed.), Handbook of theory and research for the sociology of education (pp. 241-258). New York, NY: Greenwood.

Collom, E. (2007). Alternative movements. In G. Anderson \& K. G. Herr (Eds.). Encyclopedia of activism and social justice (pp. 76-77). Thousand Oaks, CA: Sage.

Eisner, E., \& Vallance, E. (1974). Conflicting conceptions of curriculum. Berkeley, CA: McCutchan Publishing Corporation.

Farenga, P., \& Ricci, C. (2016). Growing without schooling volume 1 (GWS: The complete collection). Medford, MA: HoltGWS LLC.

Gorski, P. (1999, November). A brief history of multicultural education. Retrieved from http://www.edchange.org/multicultural/papers/edchange_history.html

Gray, P., \& Riley, G. (2013). The challenges and benefits of unschooling according to 232 families who have chosen that route. Journal of Unschooling and Alternative Learning, 7(14), 1-27.

Helms, J. E. (2014). A review of White racial identity theory: The sociopolitical implications of studying White racial identity in psychology. In S. Cooper \& K. Ratele (Eds.), Psychology serving humanity: Proceedings of the $30^{\text {th }}$ International Congress of Psychology, volume 2, (pp. 12-27). London, England: Psychology Press.

Hsieh, H. F., \& Shannon, S. E. (2005). Three approaches to qualitative content analysis. Qualitative Health Research, 15(9), 1277-1288.

"Is Forrest Carter really Asa Carter? Only Josey Wales may know for sure." (1976, August 26). New York Times. Retrieved from http://www.nytimes. com/1976/08/26/archives/is-forrest-carter-really-asa-carter-only-joseywales-may-know-for.html

Jupp, J. C., \& Sleeter, C. E. (2016). Interview of Christine Sleeter on multicultural education: Past, present, and key future directions. National Youth-At-Risk Journal 1(2), 8-26. Retrieved from http://digitalcommons.georgiasouthern. edu/nyar/vol1/iss2/2/

Kapitulik, B. (2013). Home schooling. Sociology of education: An A-Z guide. Ipswich, MA: Credo Reference.

Kapitulik, B. (2011). Resisting schools, reproducing families: Gender and the politics of homeschooling. [Doctoral dissertation]. Retrieved from Open Access Dissertations. (Paper 469) http://scholarworks.umass.edu /open_access_dissertations/469/ 
Kirschner, D. H. (2008). Producing unschoolers: Learning through living in a US education movement (Unpublished doctoral dissertation). University of Pennsylvania, Philadelphia, PA.

Krippendorf, K. (2013). Content analysis: An introduction to its methodology ( $3^{\text {rd }}$ ed.). Los Angeles, CA: Sage Publications.

Kunzman R. (2014). Homeschooling. In D. C. Phillips (Ed.), Encyclopedia of educational theory and philosophy (Volume 1, pp. 392-393). Thousand Oaks, CA: Sage Publications.

Lee, E., Menkart, D., \& Okazawa-Rey, M. (1998). Beyond heroes and holidays: A practical guide to $\mathrm{K} 12$ antiracist, multicultural education and staff development ( $2^{\text {nd }}$ ed.). Upper Marlboro, MD: McArdle Printing.

Mayberry, M. (2007). Home schooling. In K. Borman, S. Cahill, \& B. Cotner (Eds.) Gender and education: An encyclopedia. Westport, CT: Praeger.

Michel, J., Shen, Y. K., Presser Aiden, A., Veres, A., Gray, M. K., The Google Books Team,...Lieberman Aiden, E. (2010). Quantitative analysis of culture using millions of digitized books. Science, 331. Retrieved from http://science.sciencemag.org/content/sci/suppl/2010/12/16/science.11996 44.DC1/Michel.SOM.pdf

Miller, R. (2004). Educational alternatives: A map of the territory. Retrieved from http://www.educationrevolution.org/store/resources/alternatives/mapofland scape/

Miner, B. (2007). Taking multicultural, anti-racist education seriously: An interview with Enid Lee. In W. Au, B. Bigelow, \& S. Karp (Eds.), Rethinking our classrooms (Volume 1, pp. 15-17). Milwaukee, Wl: Rethinking Schools.

Morrison, K. (2016). Unschooling democracy. In P. R. Carr, P. L. Thomas, B. Porfilio, \& J. Gorlewski (Eds.), Democracy and decency: What does education have to do with it? (pp. 165-179). Charlotte, NC: Information Age Publishers.

Morrison, K. (in press). Unschooling and social justice/multicultural education: (Un)Realized potential. Other Education.

National Center for Education Statistics. (2016). Table 206.10. Number and percentage of homeschooled students ages 5 through 17 with a grade equivalent of kindergarten through 12th grade, by selected child, parent, and household characteristics: 2003, 2007, and 2012 [table]. Digest of Education Statistics. Retrieved from https://nces.ed.gov/programs/digest/ d15/tables/dt15_206.10.asp?current=yes

Neumann, A., \& Guterman, O. (2017). Structured and unstructured homeschooling: A proposal for broadening the taxonomy. Cambridge Journal of Education, 47(3), 355-371.

Nieto, S., \& Bode, P. (2018). Affirming diversity: The sociopolitical context of multicultural education $\left(7^{\text {th }}\right.$ ed.). New York, NY: Pearson. 
Petrovic, J. E., \& Rolstad, K. (2016). Educating for autonomy: Reading Rousseau and Freire toward a philosophy of unschooling. Policy Futures in Education, 1-17. https://doi.org/10.1177/1478210316681204

Ray, B. D. (2012). Homeschooling and diversity. In J. A. Banks (Ed.), Encyclopedia of diversity in education (pp. 1085-1089). Thousand Oaks, CA: Sage Publications.

Ricci, C. (2011). Unschooling and the willed curriculum. Encounter: Education for Meaning and Social Justice, 24(3), 45-48.

Schenwar, M. (2008, Winter). Learning curve: Radical unschooling moms are changing the stay-at-home landscape. Bitch, 38, 27-32. Retrieved from https://www.bitchmedia.org/article/learning-curve

Wheatley, K. F. (2009). Unschooling: An oasis for development and democracy. Encounter: Education for Meaning and Social Justice, 22(2), 27-32.

\section{Author Contact}

Sarah Chase: schase6@radford.edu, Radford University, 801 East Main St., Radford, VA 24142, U. S. A.

Kristan Morrison: kmorrison12@radford.edu, Radford University, P.O. Box 6959, Radford, VA 24142, U. S. A. 